\title{
The prevalence and mode of inheritance of Carabelli trait in the Sinhalese
}

*Upul Dissanayake', MS Chandrasekera², ER Wikramanayake ${ }^{3}$.

The Ceylon Journal of Medical Science 2004; 47: 7-15

\section{Abstract}

The prevalence and mode of inheritance of Carabelli trait has been studied in 1040 Sinhalese ( 561 males and 479 females, age range 20 to 30 yrs). Carabelli trait is one of the more common dental traits occurring most frequently on the mesio-lingual cusp of the first upper permanent molars. The trait when present is categorized as pit, groove, cusp without free tip or well developed cusp. The prevalence of Carabelli trait in the Sinhalese was compared with that reported for other population groups. Fifteen subjects who had well developed bilateral Carabelli cusps were randomly selected as probands for construction of pedigrees. The mode of inheritance was assessed by the frequency distribution of the trait among individuals in the pedigrees using the simple counting method. The most probable mode of inheritance was determined using different models of inheritance. The prevalence of Carabelli trait in the Sinhalese is $38 \%$. The trait is inherited autosomal dominant.

Key words: Carabelli trait, Mendalian inheritance

\section{Introduction}

The Carabelli trait is a fairly common dental trait seen on the first permanent maxillary molars. When present it is on the lingual surface of the mesio-lingual cusp about midway between its cusp tip and the cervical margin. The Carabelli trait takes the form of a groove, pit, cusp without free tip or a well developed cusp. The trait may be unilateral or bilateral. Different types of trait expression on left and right side in the same individual has been reported (1).

Carabelli trait has always been a fascinating morphological trait for dentists, genericists and anthropologists. As enamel is the hardest tissue in the body, teeth preserve longer than any other human remains. As such, teeth are equally accessible to the investigator both in fossils and in the living and in the laboratory as well as in the field. Therefore continuity between living and ancestral or skeletal populations can be established more easily with dentition. Observation of teeth in the oral cavity is also noninvasive and inexpensive. Collection of frequency data even from large population groups is not difficult. However, presence of the trait, make the upper molars more prone to caries. The treatment becomes even more difficult due to problems in adopting instruments.

The frequency of the Carabelli trait varies from population to population(2). Variations in the frequencies within the population

1. Division of General Pathology, Faculty of Dental Sciences, University of Peradeniya.

2. Department of Anatomy, Faculty of Medicine.

3. Emeritus Professor., University of Peradeniya. 
groups have also been reported $(3,4)$. Carbonell reported that this trait is of low prevalence in Mongoloids (Chinese and Japanese) but of high prevalence in white Caucasians(5). Since then, Scott (1980), Alvesalo et al, (1975) and Kieser (1984) have reported high frequencies for the trait in white Caucasian populations $(2,6,7)$. The few available studies show that the frequency of the trait in Negroids was comparatively low(8). No comprehensive reports are available for the Indian subcontinent except Kannapan's study in which the reported prevalence for the trait was $52.77 \%(9)$.

The mode of inheritance of the Carabelli trait has been in question. Dietz (1944) and Tsuji (1958) claimed that the trait may be controlled by a single dominant gene $(10,11)$. Kraus (1951) proposed that the Carabelli trait is determined by two co-dominant autosomal alleles(12). Goose and Lee (1971) proposed a polygenic model of inheritance (13).

The aim of the present study is to establish the prevalence and the mode of inheritance of Carabelli trait in the Sinhalese.

\section{Population and Methods}

The study sample consisted of undergraduates of the University of Peradeniya in the age range 20 to 30 years. Individuals with mixed parentage up to the three generation were excluded from the study. Subjects who had undergone extraction of upper first permanent molars and/or restoration of teeth where the restoration had distorted the morphology of the teeth under study were excluded also. The sample for the prevalence of Carabelli trait was 1040 (561 males and 479 females).
Interview, examination and recording of the data were done by a single examiner to eliminate the inter observer variability. Intraexaminer variability was assessed by rescoring $5 \%$ of the subjects examined in a particular day.

The palatal surfaces of the mesio-lingual cusp of the left and right molars of the subjects were examined with mirror and probe for the presence or absence of the Carabelli trait. When present the Carabelli trait was graded as I-IV, pir (1), groove (11), cusp without free tip (111), and well developed cusp (IV) according to the classification of Goose and Lee, 1971(13). The classification of Goose and Lee is the most widely used and commonly accepted grading system of the Carabelli trait. Accuracy, reproducibility and simplicity are the reasons for this. The classification is shown diagrammatically in Figure 1.

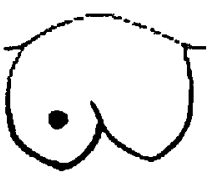

Pit(I)

Cusp without free tip(III)

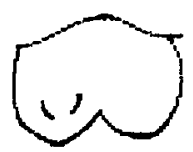

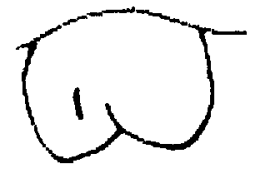

Groove (II)

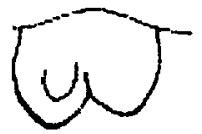

Well developed

Cusp (IV)
Figure 1. The classification of the Carabelli trait

When the trait was recorded as absent, the palatal surface of the mesio-lingual cusp of the upper first permanent molar was convex and smooth. When a catch was felt while moving the tip of the probe over the 
particular surface of the tooth, the trait was classified as a pit. When a vertical running gutter extended from the cervical margin towards the summit of the cusp was felt, the trait was classified as a groove. In the case of the Carabelli cusp without free tip, the tip of the cusp was fused with the mesio-lingual cusp of the tooth and only the prominence of the tubercle was seen. This prominence was separated from the surface of the tooth by means of two curved grooves on either side of it. A well developed cusp could be identified very easily as it projected like an additional cusp.

\section{The pedigrees}

Fifteen probands were randomly selected from 90 individuals who had bilateral well developed Carabelli cusps. Three generation pedigree charts were drawn using the proband as the principal informant. Home visits were made to examine and record the trait in the individuals on the pedigree charts. The pedigree information was cross checked for errors.

\section{Results}

Table 1 gives the percentage of males and females with different grades of Carabelli trait expressed bilaterally and unilaterally. Of the 269 subjects with bilateral Carabelli trait, 247 had the same grade of expression on both sides, and 22 subjects had different expressions of the trait on the left and right sides. These 22 subjects were recorded as having the more prominent expression observed. Chi-square test did not show a significant difference between males and females for each of the different grades of trait expression for both the bilateral and unilateral groups. $(P>0.05)$ Therefore data for both sexes were pooled for each of the different expressions. When pooled, 33 subjects had the pit and 236 showed the groove pattern. Thirteen out of 1040 had the cusp without free tip and 115 subjects had the well developed cusp. As the numbers for Grade 1 and Grade III were small, for further analysis Grade I and II and Grade III and IV were pooled as groove form and cusp form in Table 2 . As observed $26 \%$ of the total sample had the groove form of the trait whilst $12 \%$ had the cusp form.

Table 3 gives the number and percentage of males and females with Carabelli trait irrespective of both the pattern and the side of the expression. Of the 561 males 213 (38\%) had the trait. Of the 479 females 184 (38.2\%) had the trait. There is no significant difference $(P>0.05)$ in the prevalence of Carabelli trait between males and females indicating that there is no sexual dimorphism in the trait. The data of males and females when pooled showed that from a total of 1040 subjects 397 had the Carabelli trait giving an overall prevalence of $38 \%$.

Table 4 gives the total number of subjects on the informative side of the pedigree and number of subjects positive and negative for the trait for each pedigree. Of a total of 192 informative subjects 92 ( 42 males 50 females) had the trait and 100 subjects ( 47 males 53 females) did not have the trait. There was no significant difference in the prevalence of the trait between males and females $(p>0.05)$. The pooled data gives a ratio of positive to negative individuals for Carabelli trait as 92:100.

\section{Discussion}

Turner (1967) studied the skeletal remains of two groups of pre-historic Koniag Eskimos 
for the Carabelli trait and observed a prevalence of $34 \%$ and $52.6 \%$ respectively(4). However, prevalence of the trait for two groups of contemporary Koniag Eskimos in their study was $76.1 \%$ and $73.7 \%$. The suggested reason for higher frequencies in the living was due to European admixture. Barnes (1969) observed a low prevalence of $9.8 \%$ in a large population of East African Negroids(8). All forms of the trait were included in this study. A prevalence of $46 \%$ and $36.4 \%$ was observed in coastal and inland Eskimos respectively by Bang and Hasund(3). Higher values for coastal Eskimos was attributed to admixture with Caucasians. Scott (1980) reported high prevalence for all forms of Carabelli trait in American whites (Caucasians $85 \%$ ), Bushman and Bantu (Negroids 71.5\%) and lower prevalences in Asiatic Indians $(62 \%)(2)$. However when only the tubercle form was considered the prevalence for American whites (Caucasians), Bushman and Bantu (Negroids) and Asiatic Indians were $32.7 \%, 14.2 \%$ and $9.2 \%$ respectively. Kieser (1984) studied the Carabelli trait in a Caucasian population and reported a prevalence of $75.9 \%$ for males and $76.4 \%$ for females with an overall prevalence of $76 \%(7)$.

The only published study on the Carabelli trait in Sri Lanka is that of Lukacs (14). Lukacs studied the fossil remains from Pomparippu which included 12 maxillary first permanent molars and the Carabelli trait was found in seven of those teeth (14). However, the number of individuals having the Carabelli trait was not recorded and as such the prevalence cannot be determined.

In the present study the overall prevalence for the Carabelli trait was $38 \%$ which included $26 \%$ of the groove form and $12 \%$ of the cusp form. The prevalence in the Sinhalese cannot be directly compared with those of other population studies already referred to due to differences in the grading. In some studies only cusp forms were considered for the overall prevalence and in others both cusp form and the groove were taken together.

The pedigree charts of the families of 15 random probands who had bilateral well developed Carabelli cusps were analyzed to establish the mode of inheritance of the trait(15). Though the selected probands had bilateral well developed Carabelli cusps, the subjects of the informative side showed both the groove forms and the cusp form. Four of the probands inherited the trait from the father and other five inherited it from the mother, indicating complete penetrance of the gene. Neither mother nor father of the proband showed the trait in six pedigrees and this was considered to be due to lack of penetrance. Five of them inherited the gene from the maternal side and other proband inherited it from the paternal side. A pedigree chart of a family with Carabelli trait that shows an autosomal dominant pattern of inheritance is shown in Figure 2.

In two pedigrees the trait was transmitted from father to daughter. Transmission was from father to son in two, from mother to daughter in two, and mother to son in three.

The pedigrees were further analyzed for frequency distribution using the simple counting method(16). There were 42 males and 50 females positive for the trait irrespective of the type of expression; whether the cusp form or groove form(total of 92). Forty seven males and 53 females 
were negative for the trait (total of 100). The ratio for both males and females positive for the trait was 42:50 and that for males and females negative for the trait was 47:53. As there was no significant difference between males and females for both trait positive and trait negative ratios, the data were pooled together. Of 192 informative subjects in the 15 pedigrees, 92 were positive for the trait and 100 were negative for the trait irrespective of the gender. With an autosomal dominant mode of inheritance 96 subjects would be expected to be positive from a total of 192 giving a ratio of $1: 1$ irrespective of the gender. The chi square test showed that the observed ratio of $92: 100$ is not significantly different from expected ratio of 1:1. These findings, together with the observations mentioned above demonstrate that the transmission of Carabelli trait when both cusp form and grove forms were considered, as variable expressions of the same gene to follow an autosomal dominant pattern.

In conclusion the results of the present study has established the prevalence of Carabelli trait in the Sinhalese as $38 \%$ and that the mode of inheritance as autosomal dominant when cusp form and groove forms were considered as variable expressions of the same gene.

\section{References}

1. Meredith H.V. Frequency, size, and bilateralism of Carabelli's tubercle. Journal of Dental Research 1954; 33:435-440.

2. Scott R. Population variation of Carabelli's trait. Human Biology 1980; 52 : 63-78.
3. Bang G. Hasund A. Morphologic characterization of the Alaskan Eskimo Dentition. American Journal of Physical Anthropology 1972; 37: 35-40.

4. Turner C.G. Dental genetics and microevolution in prehistoric and living Koniag Eskimo. Journal of Dentistry. 1967; 46:911-917.

5. Carbonell V.M. The tubercle of Carabelli in the Kish dentition, Mesoporamia, 3000B.C. Journal of Dental Research 1960; 39 :124-128.

6. Alvesalo L., Nuutila M., Portin P. The cusp of Carabelli-occurrence in the first upper molars and an evaluation of its variability. Acta Dontologica Scandinavia 1975; 33: 191- 197.

7. Kieser J.A., An añalysis of the Carabelli trait in the mixed deciduous and permanent human dentition. Archives of Oral Biology 1984; 29 :403-406.

8. Barnes D.S. Tooth morphology and other aspects of the Teso dentition. American Journal of Physical Anthropology 1972; 30: 183-193.

9. Kannapan J.G., Swaminathan S. A study of a dental morphological variation. Tubercle of Carabelli. Indian Journal of Dental Research 2001; 12: 145-149.

10. Dietz V. A common dental morphotropic factor; the Carabelli cusp. Journal of American Dental Association 1944; 31: 784-789. 
11. Tsuji T. Incidence and inheritance of the Carabelli's cups in a Japanese population. Japanese Journal of Human Genetics 1958; 3: 21-31.

12. Karus,B.S. Carabelli's anomaly of the maxillary molar teeth. American Journal of Human Genetics. 1951; 3:348-355.

13. Goose D.H., Lee G.H.T.R. The mode of inheritance of Carabelli's trait. Human Biology 1971; 43: 64-69.
14. Lukacs J.R. Dental anthropology and biological affinities of an iron age popularion from Pomparippu, Sri Lanka. In: Ecological Backgrounds of South Asian Prehistory. Ed: Kennedy KAR and Possehl GL 1976.

15. Mueller R.F., Young F.D. Eds. Emery's elements of medical genetics. Churchill Livingston. 1995: 77-90.

16. Stern C. Ed. Principles of human genetics. W.H. Freeman and Company 1960; 90-94.

Table 1. Percentage of males and females with different grades of Carabelli trait expressed bilaterally and unilaterally. The percentages are given in parentheses.

\begin{tabular}{|c|c|c|c|c|c|c|c|}
\hline \multirow[t]{2}{*}{ Grade } & \multicolumn{3}{|c|}{ Bilateral } & \multicolumn{3}{|c|}{ Unilateral } & \multirow{2}{*}{$\begin{array}{l}\text { Pooled } \\
\text { Total }\end{array}$} \\
\hline & $\begin{array}{c}\text { Male } \\
561\end{array}$ & $\begin{array}{c}\text { Female } \\
479\end{array}$ & $\begin{array}{l}\text { Total } \\
1040\end{array}$ & $\begin{array}{c}\text { Male } \\
561\end{array}$ & $\begin{array}{c}\text { Female } \\
479\end{array}$ & $\begin{array}{l}\text { Total } \\
1040\end{array}$ & \\
\hline $\begin{array}{c}\text { Grade } \\
\text { I }\end{array}$ & $\begin{array}{c}8 \\
(1.5 \%)\end{array}$ & $\begin{array}{c}14 \\
(2.9 \%)\end{array}$ & $\begin{array}{c}22 \\
(2.2 \%)\end{array}$ & $\begin{array}{c}6 \\
(1.1 \%)\end{array}$ & $\begin{array}{c}5 \\
(1.5 \%)\end{array}$ & $\begin{array}{c}11 \\
(1.1 \%)\end{array}$ & 33 \\
\hline $\begin{array}{l}\text { Grade } \\
\text { II }\end{array}$ & $\begin{array}{c}84 \\
(14.7 \%)\end{array}$ & $\begin{array}{c}54 \\
(10.5 \%)\end{array}$ & $\begin{array}{c}138 \\
(12.7 \%)\end{array}$ & $\begin{array}{c}53 \\
(9.5 \%)\end{array}$ & $\begin{array}{c}45 \\
(9.4 \%)\end{array}$ & $\begin{array}{c}98 \\
(9.5 \%)\end{array}$ & 236 \\
\hline $\begin{array}{l}\text { Grade } \\
\text { III }\end{array}$ & $\begin{array}{c}5 \\
(0.2 \%)\end{array}$ & $\begin{array}{c}6 \\
(0.5 \%)\end{array}$ & $\begin{array}{c}11 \\
(0.3 \%)\end{array}$ & $\begin{array}{c}1 \\
(0.2 \%)\end{array}$ & $\begin{array}{c}1 \\
(0.3 \%)\end{array}$ & $\begin{array}{c}2 \\
(0.2 \%)\end{array}$ & 13 \\
\hline $\begin{array}{l}\text { Grade } \\
\text { IV }\end{array}$ & $\begin{array}{c}46 \\
(7.84 \%)\end{array}$ & $\begin{array}{c}52 \\
(9.60 \%)\end{array}$ & $\begin{array}{c}98 \\
(8.65 \%)\end{array}$ & $\begin{array}{c}10 \\
(1.74 \%)\end{array}$ & $\begin{array}{c}7 \\
(1.46 \%)\end{array}$ & $\begin{array}{c}17 \\
(0.19 \%)\end{array}$ & 115 \\
\hline
\end{tabular}


Table 2. Percentage of subjects with groove form and cusp form of the Carabelli trait

\begin{tabular}{|c|c|c|}
\hline Form of the trait & Number with trait & Percentage \\
\hline $\begin{array}{c}\text { Groove form } \\
\text { (Grades I \& II) }\end{array}$ & 269 & $25.9 \%$ \\
\hline $\begin{array}{c}\text { Cusp form } \\
\text { (Grades III \& IV) }\end{array}$ & 128 & $12.4 \%$ \\
\hline
\end{tabular}

Table 3: Number and percentage of males and females with Carabelli trait

\begin{tabular}{|l|c|c|c|}
\hline Sex & Total Number & Number with trait & Number without trait \\
\hline Male & 561 & $213(38 \%)$ & $348(62.1 \%)$ \\
\hline Female & 479 & $184(38.5 \%)$ & $295(61.6 \%)$ \\
\hline Total & 1040 & $397(38.2 \%)$ & $643(62.4 \%)$ \\
\hline
\end{tabular}


Table 4. Total number of informative, positive and negative subjects of the 15 pedigree charts

\begin{tabular}{|c|c|c|c|c|c|c|c|c|c|c|}
\hline \multirow{2}{*}{$\begin{array}{l}\text { Pedigree } \\
\text { number }\end{array}$} & \multicolumn{3}{|c|}{ Informarive subjects } & \multicolumn{3}{|c|}{ Positive subjects } & \multicolumn{3}{|c|}{ Negative subjects } & \multirow{2}{*}{$\begin{array}{c}\text { Ratio } \\
\text { +ve:-ve }\end{array}$} \\
\hline & Male & Female & Total & Male & Female & Total & Male & Female & Total & \\
\hline 1 & 4 & 8 & 12 & 2 & 3 & 5 & 2 & 5 & 7 & $5: 7$ \\
\hline 2 & 5 & 10 & 15 & 3 & 4 & 7 & 2 & 6 & 8 & $7: 8$ \\
\hline 3 & 5 & 5 & 10 & 2 & 3 & 5 & 3 & 2 & 5 & $5: 5$ \\
\hline 4 & 8 & 8 & 16 & 3 & 4 & 7 & 5 & 4 & 9 & $7: 9$ \\
\hline 5 & 7 & 7 & 14 & 3 & 4 & 7 & 4 & 3 & 7 & $7: 7$ \\
\hline 6 & 2 & 7 & 9 & 1 & 4 & 5 & 1 & 3 & 4 & $5: 4$ \\
\hline 7 & 5 & 8 & 13 & 3 & 3 & 6 & 2 & 5 & 7 & $6: 7$ \\
\hline 8 & 9 & 9 & 18 & 5 & 4 & 9 & 4 & 5 & 9 & $9: 9$ \\
\hline 9 & 7 & 10 & 17 & 4 & 4 & 8 & 6 & 3 & 9 & $8: 9$ \\
\hline 10 & 6 & 12 & 18 & 3 & 5 & 8 & 3 & 7 & 10 & $8: 10$ \\
\hline 11 & 7 & 4 & 11 & 3 & 2 & 5 & 4 & 2 & 6 & $5: 6$ \\
\hline 12 & 4 & 4 & 9 & 2 & 3 & 5 & 2 & 2 & 4 & $5: 4$ \\
\hline 13 & 4 & 4 & 8 & 3 & 1 & 4 & 3 & 1 & 4 & $4: 1$ \\
\hline 14 & 7 & 4 & 11 & 3 & 2 & 5 & 4 & 2 & 6 & $5: 6$ \\
\hline 15 & 4 & 7 & 11 & 2 & 4 & 6 & 2 & 3 & 5 & $6: 5$ \\
\hline Total & 84 & 108 & 192 & 42 & 50 & 92 & 47 & 53 & 100 & $92: 100$ \\
\hline
\end{tabular}




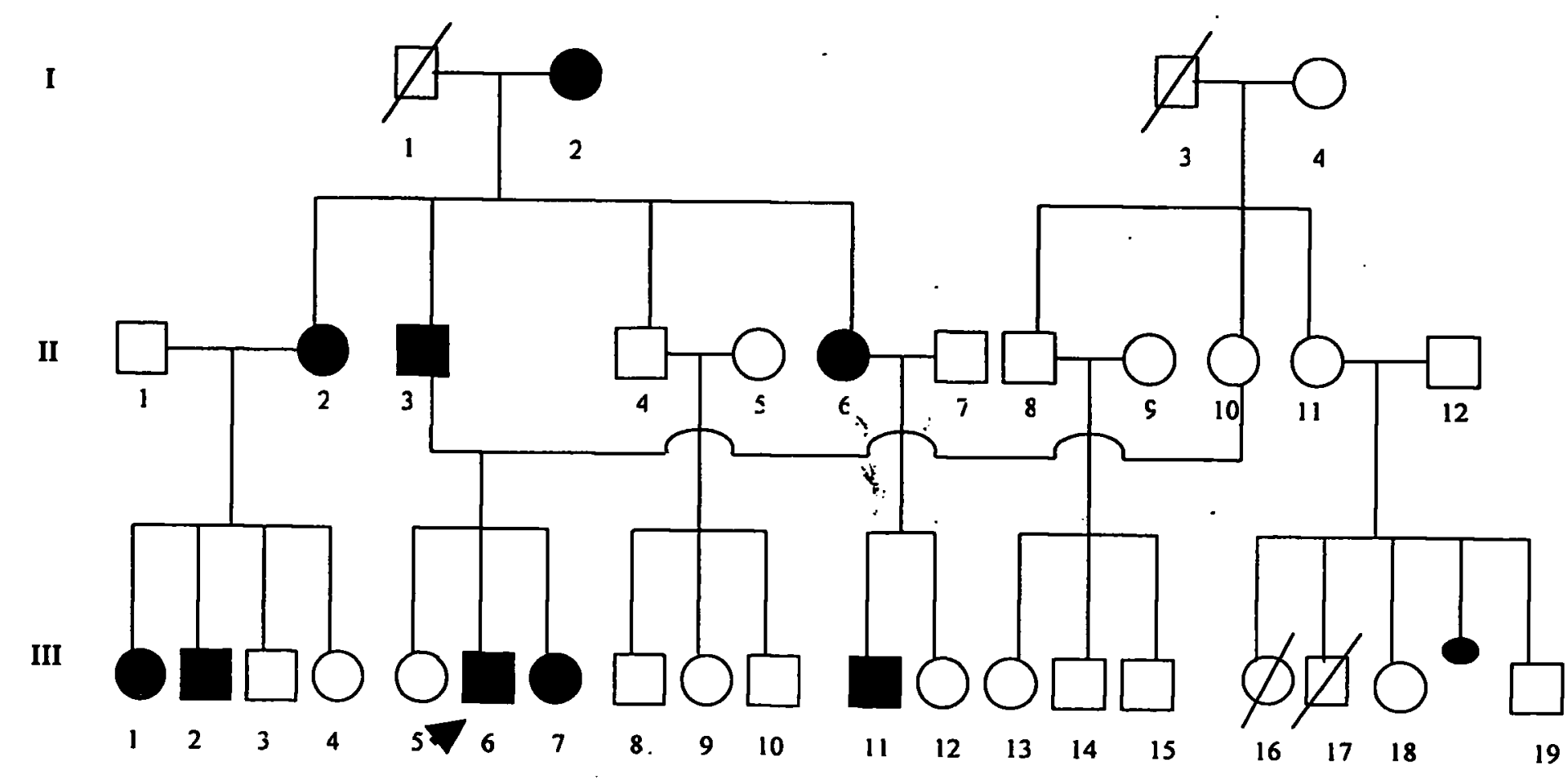

$\square^{\text {Male with trait }} \square$ Male without trail $\varnothing_{\text {Dead }} \nabla$ Proband $\bigcirc$ Female with trait

Female without trait Stillbirth I = Generation I, II = Generation II, III = Generation III

Figure 2. The pedigree chart of one family with Carabelli trait.

(All the individuals in generation II \& III were examined). 